\title{
The Interrelationship of Instrumental, Integrative, Intrinsic, and Extrinsic Motivations and the Lexical-oriented Knowledge among Persian EFL Language Learners
}

\author{
Kamal Heidari Soureshjani \\ Islamic Azad University, Shahrekord Branch, Shahrekord, Iran \\ Email: k_tefl_h@yahoo.com \\ Noushin Naseri \\ Shiraz University, International Division, Shiraz, Iran \\ Email: Noushin_nasseri@hotmail.com
}

\begin{abstract}
It is axiomatic that affective factors play crucial roles in learning a language. Among the numerous affective factors motivation has a salient role. The present study served as an attempt to shed light on the point that is there any interrelationship between the four different types of motivation (intrinsic, extrinsic, instrumental, and integrative) and the lexical-oriented knowledge of Persian language learners. To do so, 360 Persian EFL language learners were randomly selected and three different instruments, two questionnaires on motivation and a vocabulary test were administered among them to respond. The results of the study revealed that first of all, there was a positive but weak correlation between the two main variables of the study. Secondly, it became evident that there was a significant difference just between the instrumental and intrinsic types of motivation. The results of the study will provide substantial implications for better recognition of affective needs of language learners and consequently, causing conditions for more effective language learning.
\end{abstract}

Index Terms - intrinsic motivation, extrinsic motivation, instrumental motivation, integrative motivation, lexical knowledge

\section{INTRODUCTION}

It has been, through different studies, a truism that there are various factors affecting the language teaching and learning process. Among these different factors, affective factors in general and motivation in particular play an important role. Moreover, motivation has been widely acknowledged by both teachers and researchers as one of the key factors that influences the rate and success of the second or foreign language learning. For example, Research shows that those students who have higher motivation are more successful and efficient in their learning (for example, Ely, 1986; Gardner, 2000). Moreover, the original impetus in second or foreign language motivation research comes from the social psychology due to the fact that learning the language of another community simply cannot be separated from the learners' social dispositions towards the speech community in question. Gardner and Gardner and Lambert (1972) mentioned two types, or better to say, two orientations for motivation: integrative-oriented motivation and instrumental-oriented motivation. The first former applies to cases when language is learned as a desire to integrate into the target language community; and the latter refers to cases where language is learned with the intention of achieving a certain external reason like getting a job.

\section{BACKGROUND TO THE STUDY}

In the literature on motivation, there is no single, integrated definition of motivation. Ellis (1994) for instance in an overview of research on motivation asserted that motivation refers to the extent to which language learners persevere in learning, and to what kinds of behavior they exert and their actual achievement. Wlodwoski (1985) also explained motivation as:

"the processes that can (a) arouse and instigate behavior, (b) give direction or purpose to behavior, (c) continue to allow behavior to persist, and (d) lead to choosing or preferring a particular behavior" (p. 2)".

Gardner's (1985) definition is somehow related to this definition. He defined L2 motivation as "the extent to which an individual works or strives to learn the language because of a desire to do so and the satisfaction experienced in this activity" (p. 10). Gardner (1985) also proposed a more comprehensive and accurate explanation for the concept of motivation. He noted that motivation is conceptualized as a set of variables. That is, it is a combination of effort plus desire to achieve the goal of learning and also a combination of the language plus favorable attitudes towards learning 
the language. In addition, motivation is hypothesized to have a direct effect on L2 achievement and is itself purportedly influenced by a number of other social-psychological variables. And finally, Brown (2001) in his study stated that motivation simply refers to the intensity of one's impetus to learn. It is conspicuous in all these definitions that learner's attitude, degree of effort, investment of time, and also his amount of energy contribute in determining the extent one is motivated in language learning.

However, there are various taxonomies as to different types of motivation. One common categorization divides motivation into two types of instrumental and integrative-oriented types of motivations. Instrumental motivation refers to the situations where the purpose of language learning is to get a benefit, for example, to get a job, or to get higher payment. Integrative motivation in contrast, is considered as the opposite of instrumental motivation. The purpose of this motivation is not to get a benefit from learning the language, but language is learnt just to be integrated in that language and its culture.

On the basis of another classification, motivation is divided into two types of extrinsic and intrinsic. To make a relationship between this classification and the above-mentioned one, it could be assumed that extrinsic motivation is somehow related to instrumental motivation and intrinsic motivation is related to integrative motivation. Therefore, extrinsic motivation is related to the purpose of getting something in the outside world like getting a prize. But in contrast, intrinsic motivation pertains to internal factors and learning the language just for itself.

As to the relationship between motivation and learning strategies, some studies found that motivation has a far-reaching relationship with the learners' use of different types of strategies. Oxford and Nyikos (1989) for example, asserted that the degree of motivation of students is the single most powerful influence on the choice of language learning strategies.

One aspect of language which is considered as one of the most important aspects of every language is vocabulary. The significance of this part of language is to the extent that even some researchers equate the learning process of a language with learning and in fact, knowing the words of that language. Although this claim is somehow an exaggeration, however, the significant role of vocabulary in learning a language should not be looked down upon. Moreover, researchers and theorists have severally admitted the fact that vocabulary knowledge is multi-faceted. In other words as Harley (1996) righty noted, it is a disarmingly simple term for a complex multidimensional phenomenon. Due to this complexity, classroom teachers must take a more comprehensive approach to vocabulary development in order for students to reach a higher quality and quantity of L2 output (Sanaoui, 1996; Swain, 1996). They state that there are three facets of this complexity: (a) receptive versus productive vocabularies, (b) breadth versus depth of vocabularies, and (c) direct teaching versus contextual inferencing.

Vocabulary learning may occur implicitly in language arts classrooms as well as content area classrooms, especially with regard to incidental word learning through context. Research studies have shown that upper grade students across ability levels can acquire vocabulary incidentally through reading and listening (for example, Nagy \& Herman, 1987). Besides, Nagy and Herman also found that new words representing known concepts were more easily learned incidentally during independent reading than words that were more conceptually difficult. In another study, Swanburn and de Glopper (1999) found that middle level and secondary readers acquire partial understanding of approximately $15 \%$ of the unfamiliar words they encounter while reading. These studies support wide reading as an important component in a comprehensive vocabulary program. Reading widely and frequently is not only related to school achievement but also to increased vocabulary acquisition. In their study on the amount of time students spend reading, Anderson, Wilson, and Fielding (1988) found a positive correlation between the amount of time fifth grade students spend reading and their reading achievement scores on a standardized reading test. Students with scores at the 98th percentile on the test read approximately 5 million words per year, while those students scoring at the 50th percentile read approximately 600,000 words per year.

As to the vocabulary learning ways, there exist conflicting views among language professionals concerning the relative superiority of two approaches to learning second language vocabulary: learning words in context vs. learning words out of context. Convictions are strong among many language professionals that contextualized vocabulary learning is more effective than learning words in lists. Oxford and Scarcella (1994), for example, observe that while decontextualized learning (word lists) may help students memorize vocabulary for tests, students are likely to rapidly forget words memorized from lists. McCarthy (1990) argues that a word learned in a meaningful context is best assimilated and remembered. However, most studies have failed to produce findings favoring context-dependent vocabulary learning (e.g. Morgan and Bailey, 1943; Wind and Davidson, 1969; Gershman, 1970, Tudor and Hafiz, 1989, Hulstjin, 1992 ).

Vocabulary knowledge plays also an important role in reading comprehension. Researchers tend to agree that vocabulary knowledge is a major prerequisite and causal factor in comprehension and that there is a relationship between vocabulary size and reading comprehension. Some studies have investigated this relationship and used vocabulary size as a predictor variable for reading comprehension (Hu \& Nation, 2000; Laufer 1992, 1997; Liu Na \& Nation, 1985). In Koda (1989) further examined the correlation between vocabulary tests and two reading tests. The result of her study showed that vocabulary knowledge contributes to students' reading comprehension in Japanese, and that there was a correlation coefficient of 0.74 between the vocabulary test scores and the comprehension test scores.

Regarding all the above-cited works and explanations and also admitting that few studies have dealt with the role of 
the four main types motivation in the depth of vocabulary knowledge especially in EFL contexts including Iran, this study served as an attempt to consider the relationship between instrumental, integrative, intrinsic, and extrinsic motivations and the depth of vocabulary knowledge among Iranian EFL language learners. To clarify its purpose, in this study it was tried to determine firstly, if the four types of motivation have any role in learning the vocabulary part of language, and secondly, in the case of existing such a role, which one has the most effective and which one the least effective role. The study, in fact, attempts to address the following research question:

Is there any relationship between the four types of motivation and the depth of vocabulary knowledge of the Iranian EFL language learners?

Conducting studies like the present one is useful for language teachers because the results of the study may help them be able to employ the approaches which are consistent with the motivations of their students and subsequently, make them learn vocabulary more effectively. It is also significant for language learners since by knowing about this relationship they will be able to know the most suitable kind(s) of motivation for vocabulary learning and so by boosting that kind of motivation in them they will be more efficient in their learning of vocabulary part of language.

\section{Methodology}

\section{A. Participants}

The participants of the present study were, totally, 360 Persian EFL language learners of three well-known language institutes of Shiraz, Iran. In each of the institutes 120 male and female were selected on the basis of their availability. They were all studying the intermediate average age of 20 . with the average age of 20 years.

\section{B. Materials}

In order to collect the desired data, two different questionnaires and a test were employed. The questionnaires were derived from Laine (1987) and validated by Salimi (2000). The first one was related to extrinsic and intrinsic motivations (See Appendix B). This questionnaire consists of two parts: the first part provides personal information about the participants. And the second part which involves twenty one items in the Likert scale format and try to get information on those reasons of learning the vocabulary part of language which are related to internal and external sources of motivation.

The other questionnaire utilized in the study was the questionnaire which gathered data on the instrumental and integrative motivations of language learners (See Appendix C). This questionnaire, like the previous one, consists of two sections: the first section is about the personal information of the participants and the second section consists of twenty items in the Likert scale format. One more point regarding this questionnaire is that Sedaghat (2001) states that Salimi (2000) estimated its reliability by Cronbach Alpha; and it turned out to be .71. However reliability estimation repeated in this study for the sake of certainty and it turned out to be almost .76.

The third and the last instrument was the Vocabulary Depth test which collects information about the vocabulary knowledge of the participants (See Appendix A). This test consists of forty vocabulary items which are aimed at assessing the vocabulary power of language learners in different topics. The test has been proved to be reliable by Ieav (1988). Again, the reliability estimation repeated in the present study and it turned out to be .68.

\section{Data Analysis}

Having gathered the required data and in order to analyze them, the SPSS statistical program in general and first a correlational design in particular was run to investigate the relationship between the variables of the study. Second, a one-way ANOVA was also run to see the influence of motivations on the vocabulary knowledge performance of the participants.

\section{RESULTS}

In this part of the paper the main results of the study are presented and detailed. Table 1 represents the descriptive statistics including the mean, standard deviation, and other fundamental information as to the variables of the study. As it is conspicuous from the table, the mean obtained from the participants' attitudes about the four types of the motivation is remarkably high when compared with the number of participants (2.73). It implies that the participants are more or less consistent with each other regarding their attitudes towards the questionnaire items. Moreover, the mean obtained for the scores of the participants in the vocabulary test also shows that the scores were almost the same for the test takers (25.43). To be able to talk with more confidence and to support these findings examining the table showing the main results of correlation would be a great help.

TABLE 1

\begin{tabular}{|l|l|l|l|}
\hline \multicolumn{1}{|c}{ DESCRIPTIVE STATISTICS } \\
\hline & Mean & Std. Deviation & $\mathrm{N}$ \\
\hline motivation & 2.73 & 1.10 & 360 \\
\hline score & 25.43 & 7.61 & 360 \\
\hline
\end{tabular}


Table 2 which represents the main findings of correlation indicates a relatively low Pearson product correlation for the variables of the study $(=.188)$. The table also cast light on the point that there is a significant difference among the variables of the study $($ sig. $=.000)$.

TABLE 2

CORRELATION RESULTS

\begin{tabular}{|l|l|l|l|}
\hline \multirow{4}{*}{ motivation } & & motivation & Score \\
& Pearson Correlation & 1 & $.188^{* *}$ \\
\cline { 2 - 4 } & Sig. (2-tailed) & & .000 \\
\cline { 2 - 4 } & $\mathrm{N}$ & 360 & 360 \\
\hline \multirow{5}{*}{ score } & Pearson Correlation & $.188^{* *}$ & 1 \\
\cline { 2 - 4 } & Sig. (2-tailed) & .000 & \\
\cline { 2 - 4 } & $\mathrm{N}$ & 360 & 360 \\
\hline \multirow{2}{*}{$* *$. Correlation is significant at the 0.01 level (2-tailed). }
\end{tabular}

All in all, correlation showed that first there is a low degree of relationship among the variables of the study. It also ascertained that the variables of the study that is, motivations and the vocabulary scores are significantly different. However, it doesn't reveal where exactly these differences lay. To know about these differences one-way ANOVA was run.

The first table obtained through one-way ANOVA is table 3 presenting the descriptive information like the mean, standard deviation, and some other information regarding each of the four types of motivation. As it is evident from the table, the instrumental and intrinsic motivations possess the highest and lowest of mean respectively. It is in this sense that the participants of the study had more similar attitudes as to the instrumental motivation and less similar ideas about the intrinsic motivations of language learning.

TABLE 3.

DESCRIPTIVE DATA ON THE FOUR MOTIVATION TYPES

\begin{tabular}{|c|c|c|c|c|c|c|c|c|}
\hline & \multirow[t]{2}{*}{$\mathrm{N}$} & \multirow[t]{2}{*}{ Mean } & \multirow[t]{2}{*}{ Std. Deviation } & \multirow[t]{2}{*}{ Std. Error } & \multicolumn{2}{|c|}{$95 \%$ Confidence Interval for Mean } & \multirow[t]{2}{*}{ Minimum } & \multirow[t]{2}{*}{ Maximum } \\
\hline & & & & & Lower Bound & Upper Bound & & \\
\hline intrinsic motivation & 60 & 22.2 & 7.8 & 1.0 & 20.2 & 24.2 & 9 & 36 \\
\hline extrinsic motivation & 98 & 25.5 & 8.1 & .82 & 23.9 & 27.2 & 2 & 40 \\
\hline integral & 80 & 25.1 & 6.9 & .77 & 23.6 & 26.7 & 10 & 39 \\
\hline instrumental & 122 & 27.0 & 7.0 & .64 & 25.7 & 28.3 & 11 & 40 \\
\hline Total & 360 & 25.4 & 7.6 & .40 & 24.6 & 26.2 & 2 & 40 \\
\hline
\end{tabular}

Table 4 which shows the ANOVA results indicate that there is a significant difference with regard to the four types of the motivation ( $\mathrm{sig}=.001)$. This inference is the same as what was mentioned for the correlation results. Now in order to see the exact place of differences, let's examine the post hoc test.

TABLE 4

ANOVA RESULTS

\begin{tabular}{|l|l|l|l|l|l|}
\hline & Sum of Squares & df & Mean Square & F & Sig. \\
\hline Between Groups & 934.43 & 3 & 311.4 & 5.5 & .001 \\
\hline Within Groups & 199.09 & 356 & 55.9 & & \\
\hline Total & 208.53 & 359 & & & \\
\hline
\end{tabular}

Table 5 that is, the post hoc table, reveals that the significant difference is only between the intrinsic and instrumental motivations. But regarding all other types of motivation, there is no significant difference with regard to their relationship to each other.

TABLE 5

MULTIPLE COMPARISON RESULTS

\begin{tabular}{|c|c|c|c|c|c|c|c|}
\hline & \multirow{2}{*}{$\begin{array}{l}(\mathrm{I}) \\
\text { motivation }\end{array}$} & \multirow[t]{2}{*}{ (J) motivation } & \multirow{2}{*}{$\begin{array}{l}\text { Mean Difference } \\
(\mathrm{I}-\mathrm{J})\end{array}$} & \multirow{2}{*}{$\begin{array}{l}\text { Std. } \\
\text { Error }\end{array}$} & \multirow[t]{2}{*}{ Sig. } & \multicolumn{2}{|c|}{$95 \%$ Confidence Interval } \\
\hline & & & & & & Lower Bound & Upper Bound \\
\hline \multirow[t]{12}{*}{ Scheffe } & \multirow{3}{*}{$\begin{array}{l}\text { intrinsic } \\
\text { motivation }\end{array}$} & extrinsic motivation & -3.30 & 1.22 & .06 & -6.74 & .13 \\
\hline & & Integral & -2.89 & 1.27 & .16 & -6.48 & .69 \\
\hline & & Instrumental & $-4.79 *$ & 1.17 & .00 & -8.11 & -1.48 \\
\hline & \multirow{3}{*}{$\begin{array}{l}\text { extrinsic } \\
\text { motivation }\end{array}$} & intrinsic motivation & 3.30 & 1.22 & .06 & -.13 & 6.74 \\
\hline & & Integral & .40 & 1.12 & .98 & -2.75 & 3.57 \\
\hline & & Instrumental & -1.49 & 1.01 & .53 & -4.34 & 1.35 \\
\hline & \multirow[t]{3}{*}{ integral } & intrinsic motivation & 2.89 & 1.27 & .16 & -.69 & 6.48 \\
\hline & & extrinsic motivation & -.40 & 1.12 & .98 & -3.57 & 2.75 \\
\hline & & instrumental & -1.90 & 1.07 & .37 & -4.92 & 1.11 \\
\hline & \multirow[t]{3}{*}{ instrumental } & intrinsic motivation & $4.79 *$ & 1.17 & .00 & 1.48 & 8.11 \\
\hline & & extrinsic motivation & 1.49 & 1.01 & .53 & -1.35 & 4.34 \\
\hline & & Integral & 1.90 & 1.07 & .37 & -1.11 & 4.92 \\
\hline
\end{tabular}

*. The mean difference is significant at the 0.05 level. 


\section{DISCUSSION AND CONCLUSION}

The present study served in fact as an attempt to ascertain whether there is any relationship between the four types of motivation (instrumental, integrative, intrinsic, and extrinsic) and the depth of vocabulary knowledge of the Iranian EFL language learners. Here in this part the research question of the study is represented and discussed in detail.

Is there any relationship between the four types of motivation and the depth of vocabulary knowledge of the Iranian EFL language learners?

As to the presence or lack of any probable relationship between the two main variables of the study (motivation and depth of vocabulary knowledge), as it was above-mentioned the results of the study revealed a significant but with a very weak positive degree of relationship between them. In sharp contrast to this result there are some researchers who have reported a very strong positive relationship between the motivation and different aspects of language learning including vocabulary. Gardner (2007) for example noted that motivation plays a crucial role in different ways like classroom behavior, persistence in language study, bicultural excursions, intensive language programs, modes of acculturation, etc. in language learning. Gardner and Lambert (1972) also advocated the important role of motivation (especially integrative-oriented motivation) in the second language acquisition. The study also revealed that the only significant difference among the four types of motivations is between the instrumental and intrinsic motivations. It can be implied from this inference that the more language learners enjoy an instrumental-oriented motivation possess the less degree of intrinsic motivation they will have in their language learning process and vice versa.

In the end, it should be admitted that the present study, like any other ones, suffer from a set of limitations. Although the number of participants seems to be appropriate, one main problem with them is that they all were intermediate-level language learners hence making the findings of the study less generalizable. Moreover, in order to reach and make more reliable findings some other studies can be achieved in other foreign contexts.

APPENDIX A THE VOCABULARY TEST SAMPLE

بـ اشدمي زي ر صورت بـه سؤال هو .ددار وجود سؤال 40 ت ست اي ن در :د سد تور ال عمل

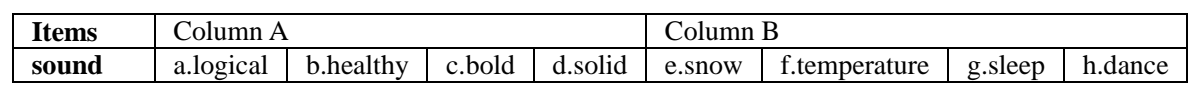

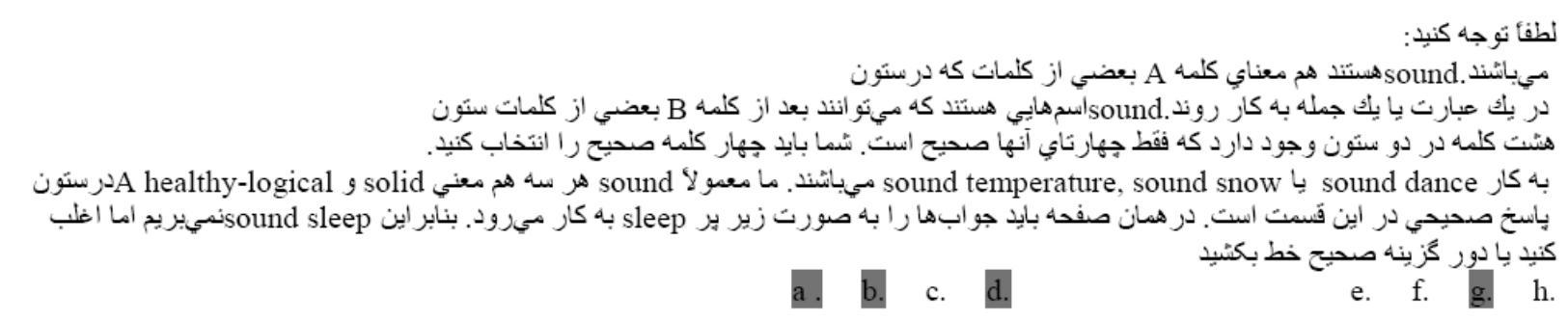

\begin{tabular}{|c|c|c|c|c|c|c|c|c|}
\hline \multirow{2}{*}{$\begin{array}{c}\text { Items } \\
\text { 1.peak }\end{array}$} & \multicolumn{4}{|c|}{ Column A } & \multicolumn{4}{|c|}{ Column B } \\
\hline & a.initial & b.top & c.crooked & d.punctual & e.time & f.performance & g.beginning & h.speed \\
\hline 2.accurate & a.exact & b.helpful & c.responsible & d.reliable & e.error & f.event & g.memory & h.estimate \\
\hline 3.dense & a.transparent & b.acceptable & c.compact & d.thick & e.hair & f.view & g.wood & h.material \\
\hline 4.troublesome & a.annoying & b.irritating & c.dangerous & d.bothersome & e.favor & f.relief & g.weeds & h.opportunity \\
\hline 5.devoted & a.dedicated & b.relevant & c.loyal & d.elected & e.follower & f.instance & g.requirement & h.patriot \\
\hline 6.wild & a.sound & b. uncultivated & c.uncivilized & d.disappointed & e.calm & f.mob & g.refinement & h.berries \\
\hline 7.insufficient & a.ungrateful & b.inexpressible & c.discontented & d.inadequate & e.lack & f.resources & g.amount & h.need \\
\hline 8.considerable & a.significant & b.outright & c.great & d.large & e.change & f.condition & g.release & h.nature \\
\hline 9.obscure & a.unclear & b.unknown & c.vague & d.old & e.product & f.appraisal & g.origin & h.demand \\
\hline 10.minute & a.tiny & b.timely & c.incorrect & d.hard & e.adjustment & f.preconception & g.imperfection & h.particle \\
\hline 11.consecutive & a.successive & b.final & c.fateful & d.required & e.attempts & f.matches & g.aspects & h.terms \\
\hline 12.narrow-minded & a.bigoted & b.intolerant & c.stupid & d.uniform & e.remark & f.creation & g.people & h.wisdom \\
\hline 13.key & a.primary & b. fundamental & c.hidden & d.false & e.issues & f.purpose & g.wealth & h.duration \\
\hline 14.overall & a.general & b.special & c.comprehensive & d.best & e.component & faction & g.responsibility & h.goal \\
\hline 15.surplus & a.valuable & b.problematic & c.strong & d.extra & e.sorrow & f.supplies & g.food & h.revenues \\
\hline 16.appealing & a.prevalent & b.likeable & c.attractive & d.pleasing & e.city & f.conflict & g.prominence & h.objection \\
\hline 17.organic & a.living & b.advanced & c.inspired & d.colorful & e.compound & f. farm & g.matter & h.requirement \\
\hline 18.vivid & a.bright & b.intense & c.intelligent & d.visual & e.description & fexception & greception & h.coloring \\
\hline 19.leading & a.foremost & b.principal & c.developed & d.competitive & e.scientist & f.society & g.work & h.producer \\
\hline 20.daring & a.brave & b.bold & c.late & d.upsetting & e.feat & f.escape & g.problem & h.sleep \\
\hline
\end{tabular}




\begin{tabular}{|c|c|c|c|c|c|c|c|c|}
\hline \multirow{2}{*}{$\begin{array}{l}\text { Items } \\
\text { 2l.celebrated }\end{array}$} & \multicolumn{4}{|c|}{ Column A } & \multicolumn{4}{|c|}{ Column B } \\
\hline & a.renowned & b.festive & c.well-known & d.famous & e.persuasion & f.recognition & g.understanding & h.play \\
\hline 22.fine & a.excellent & b.average & c.constant & d.natural & e.day & f.athlete & g.removal & h.china \\
\hline 23.powerful & a.potent & b.definite & c.influential & d. supportive & e.position & f.engine & g.repetition & h.price \\
\hline 24.conventional & a.traditinal & b.practical & c.neat & d.expensive & e.clothing & f.warfare & g.methods & h.awkwardness \\
\hline 25.deceptive & a.wishful & b.misleading & c.polite & d.dramatic & e.inspiration & f.argument & g.intent & h.appearance \\
\hline 26.crude & a.sympathetic & b.unprocessed & c.unrefined & d.rude & e.respect & f.value & g.detail & h.oil \\
\hline 27.brief & a.short & b.fleeting & c.quick & d.clear & e.help & f.summer & g.tool & h.approach \\
\hline 28.fake & a.fabulous & b.imitation & c.splendid & d.counterfeit & e.fur & f.experience & g-attraction & h.identity \\
\hline 29.remote & a.mental & b.distant & c.reasonable & d.far & e.location & f.knowledge & g.package & h.era \\
\hline 30.essential & a.vital & b.necessary & c.sensible & d.critical & e.loss & f.nutrients & g.outlook & h.luxury \\
\hline 31.adjacent & a.nearby & b.private & c.adjoining & d. genuine & e.property & f.suburbs & g.plans & h.silence \\
\hline 32.avid & a.sarcastic & b.enthusiastic & c.eager & d.reckless & e.report & f.eater & g.reader & h.request \\
\hline 33.elaborate & a.concealed & b.evolved & c.intricate & d.generous & e.void & f.precautions & g.system & h.network \\
\hline 34.terse & a.heated & b.concise & c.delicate & d.abrupt & e.attitude & freply & g.expectation & h.style \\
\hline 35.contaminated & a.rejected & b.infected & c.unclean & d.convenient & e.weather & f.news & g.site & h.needle \\
\hline 36.prolonged & a.lengthened & b.extended & c.continued & d.boring & e.willingness & f.road & g.space & h.illness \\
\hline 37.irrevocable & a.unalterable & b.irreversible & c.unchangeable & d.impossible & e.pretense & f.quantity & g.nonsense & h.step \\
\hline 38.perceptible & a.present & b.surprising & c.visible & d.initial & e.motion & f.personality & g.star & h. flaw \\
\hline 39.perpetual & a.permanent & b.unbelievable & c.everlasting & d.continual & e.level & f.cold & g.book & h.foresight \\
\hline 40.recurring & a.recent & b.repeated & c.respectable & d.resolute & e.dream & f.nation & g.complaint & h.theme \\
\hline
\end{tabular}

\section{APPENDIX B INTRINSIC \& EXTRINSIC MOTIVATION QUESTIONNAIRE}

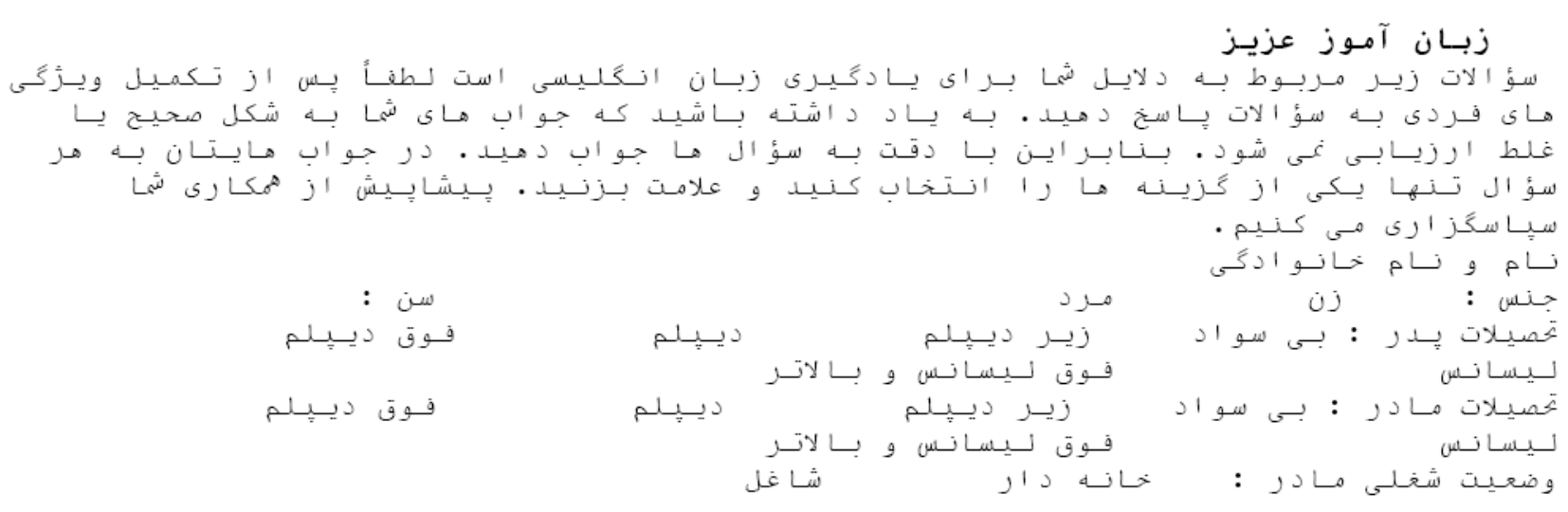




\begin{tabular}{|c|c|c|c|c|c|c|}
\hline \multirow[t]{2}{*}{ 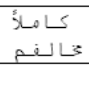 } & 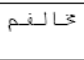 & 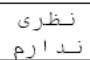 & هـو افنقم & 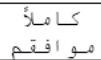 & \multicolumn{2}{|l|}{ سؤ الات } \\
\hline & & & & & 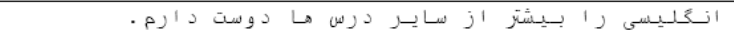 & 1 \\
\hline & & & & & 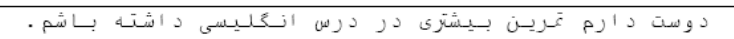 & 2 \\
\hline & & & & & 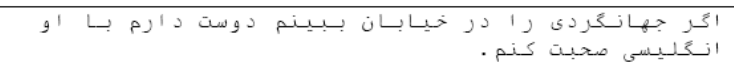 & 3 \\
\hline & & & & & 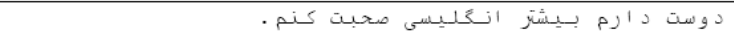 & 4 \\
\hline & & & & & 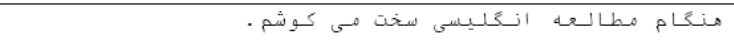 & 5 \\
\hline & & & & & 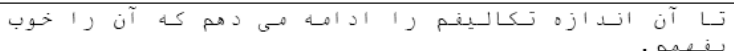 & 6 \\
\hline & & & & & 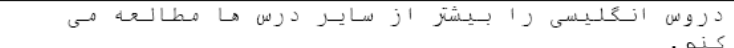 & 7 \\
\hline & & & & & 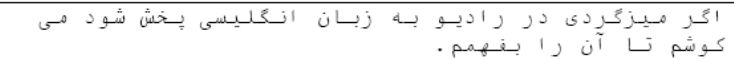 & 8 \\
\hline & & & & & 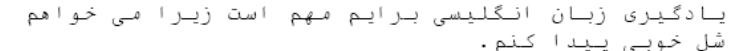 & 9 \\
\hline & & & & & 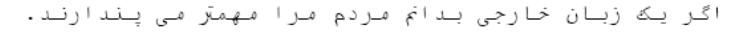 & 10 \\
\hline & & & & & 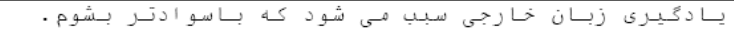 & 11 \\
\hline & & & & & 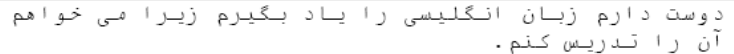 & 12 \\
\hline & & & & & 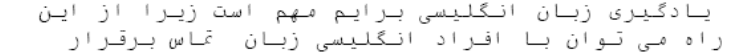 & 13 \\
\hline & & & & & 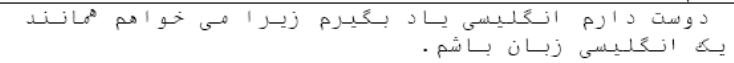 & 14 \\
\hline & & & & & 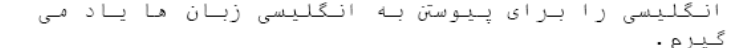 & 15 \\
\hline & & & & & 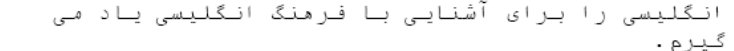 & 16 \\
\hline & & & & & 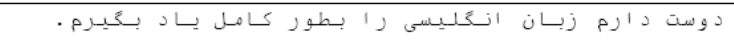 & 17 \\
\hline & & & & & 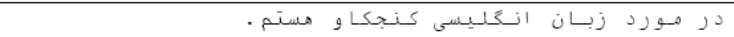 & 18 \\
\hline & & & & & 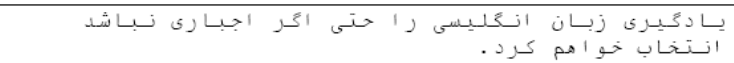 & 19 \\
\hline & & & & & 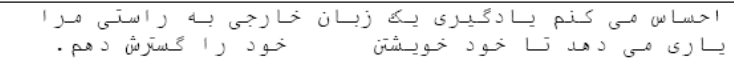 & 20 \\
\hline
\end{tabular}

\section{APPENDIX C. INSTRUMENTAL \& INTEGRATIVE MOTIVATION QUESTIONNAIRE}

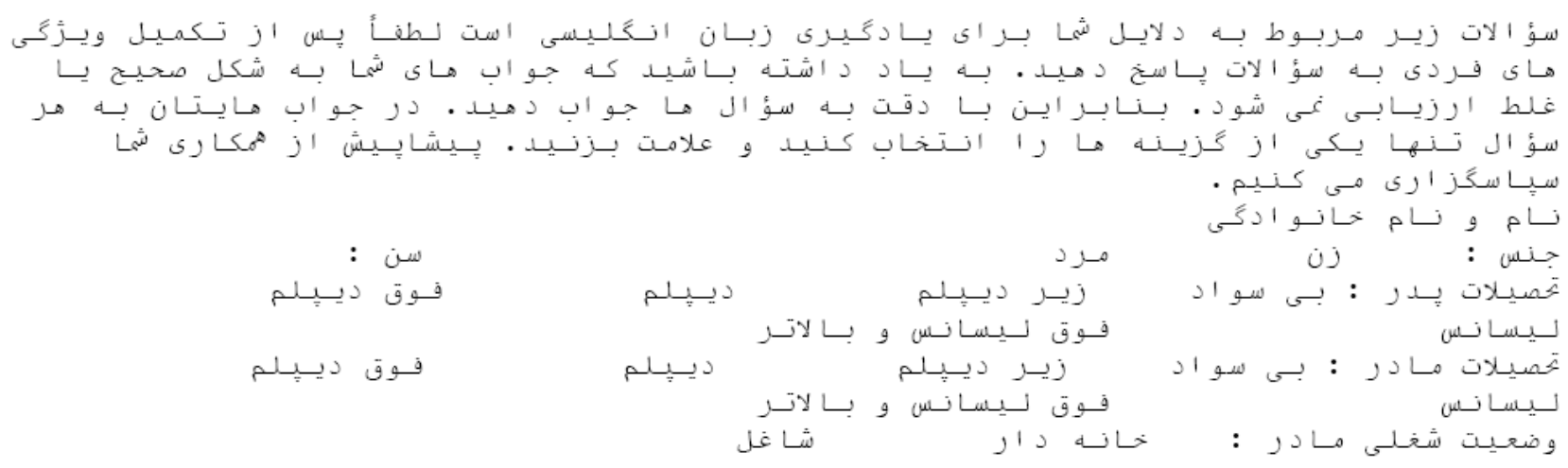




\begin{tabular}{|c|c|c|c|c|c|c|}
\hline 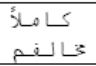 & خـالـنــم & 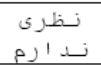 & مهو افقـم & 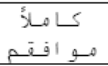 & سؤ الات & \\
\hline & & & & & 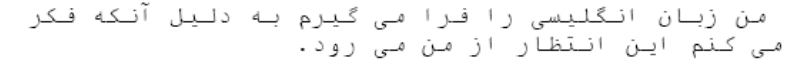 & 1 \\
\hline & & & & & 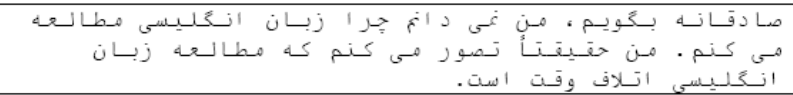 & 2 \\
\hline & & & & & 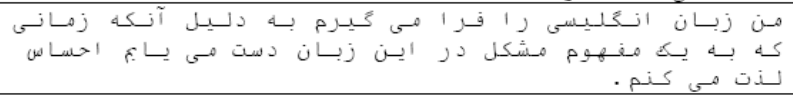 & 3 \\
\hline & & & & & 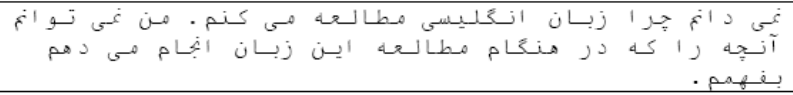 & 4 \\
\hline & & & & & 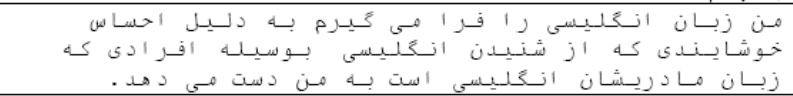 & 5 \\
\hline & & & & & 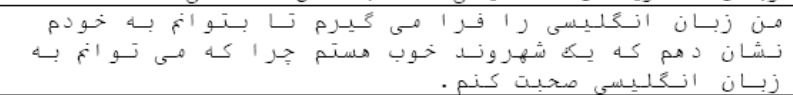 & 6 \\
\hline & & & & & 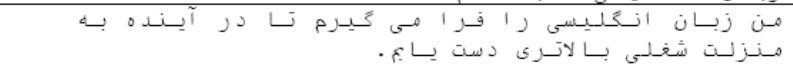 & 7 \\
\hline & & & & & 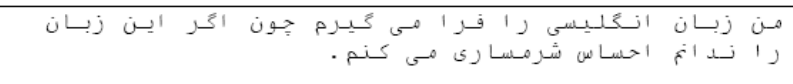 & 8 \\
\hline & & & & & 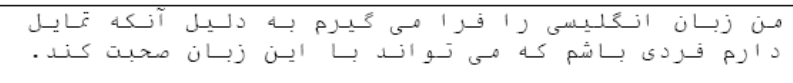 & 9 \\
\hline & & & & & 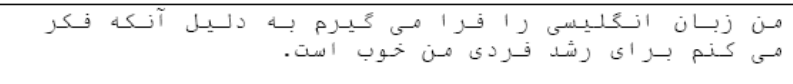 & 10 \\
\hline & & & & & 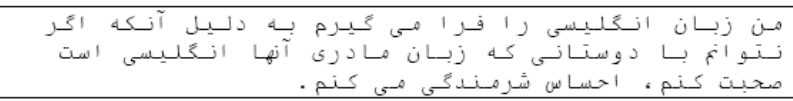 & 11 \\
\hline & & & & & 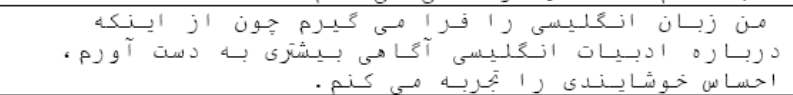 & 12 \\
\hline & & & & & 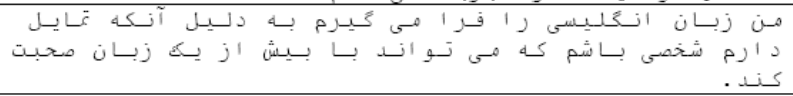 & 13 \\
\hline & & & & & 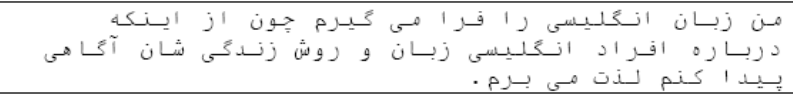 & 14 \\
\hline & & & & & 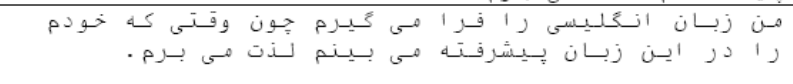 & 15 \\
\hline & & & & & 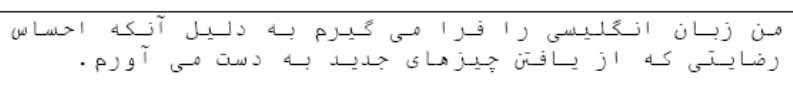 & 16 \\
\hline & & & & & 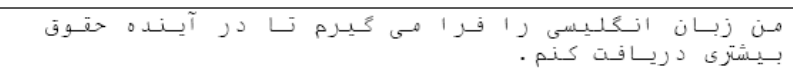 & 17 \\
\hline & & & & & 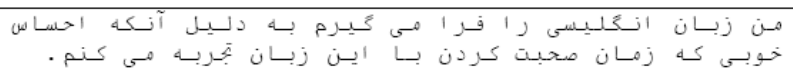 & 18 \\
\hline & & & & & 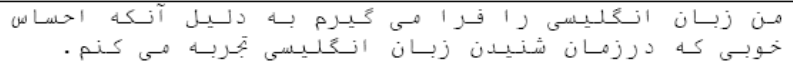 & 19 \\
\hline & & & & & 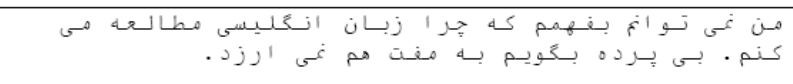 & 20 \\
\hline & & & & & 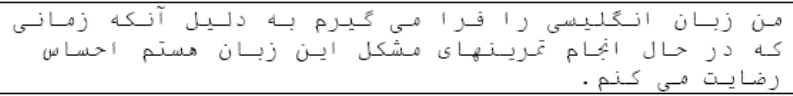 & 21 \\
\hline
\end{tabular}

\section{REFERENCES}

[1] Anderson, R. C.; Wilson, P. T. \& Fielding, L. G. (1988). Growth in reading and how children spend their time outside of school. Reading Research Quarterly 23, 285-303.

[2] Ellis, R. (1994). The study of second language acquisition. New York: Oxford University Press.

[3] Ely, C. (1986). Language learning motivation: A descriptive and causal analysis. Modern Language Journal 70, 28 - 35.

[4] Gardner, R. C. (1985). Social psychology and second language learning: the role of attitudes and motivation. London: Edward Arnold.

[5] Gardner, R. C. (2000). Correlation, causation, motivation, and second language acquisition. Canadian Psychology 41, 1-24.

[6] Gardner, R. C. (2007). Motivation and second language acquisition. Porta Linguarum 8, 9-20.

[7] Gardner, R. C., \&Lambert, W. E. (1972).Attitudes and motivation in second language learning. Rowley, MA: Newbury House. 
[8] Gershman, S.J. (1970). Foreign Language Vocabulary Learning under Seven Conditions Unpublished doctoral thesis, Columbia University, New York.

[9] Harley, B. (1996). Introduction: Vocabulary learning and teaching in a second language. The Canadian Modern Language Review, 53 (1), 3-12.

[10] Hu, M., \& Nation, I. S. P. (2000). Vocabulary Density and Reading comprehension. Reading in a Foreign Language, 13(1), 403-430.

[11] Hulstjin, J. (1992). 'Retention of inferred and given word meanings: Experiments in incidental vocabulary learning.' In P. Arnaud \& H. Béjoint (Eds.), Vocabulary and Applied Linguistics 113-25. Basingtoke: Macmillan.

[12] Ieav, P. (1988). Motivation type and their influence on vocabulary depth of language learners. Journal of Pragmatics, 12 , 342-361.

[13] Koda, K. (1989). The effects of transferred vocabulary knowledge on the development of L2 reading proficiency. Foreign Language Annals, 22, 529-540.

[14] Laine, J. E. (1987). Affective factors in foreign language learning and teaching. Cross Language Studies. Jyvaskyla: Jyvaskyla University.

[15] Laufer, B. (1992). How much lexis is necessary for reading comprehension? In Vocabulary and Applied Linguistics, (Eds), H. Bejoint and P. Arnaud. Macmillan, (p.126-132).

[16] Laufer, B. (1997). 'The lexical plight in second language reading: Words you don't know, words you think you know, and words you can't guess.' In J. Coady, and T. Huckin, (Eds.), Second Language Vocabulary Acquisition 20-34. Cambridge University Press: Cambridge.

[17] Liu, N. \& Nation, I.S.P. (1985). Factors affecting guessing vocabulary in context. RELC Journal 16(1), 33-42.

[18] McCarthy, M. J. (1990). Vocabulary. Oxford: Oxford University Press.

[19] Morgan, C.L. \& Bailey, W.L. (1943). 'The effects of context on learning a vocabulary.' Journal of Educational Psychology 38, 561-65.

[20] Nagy, W., \& Herman, P. (1987). Breadth and depth of vocabulary knowledge: Implications for acquisition and instruction. In M.G. KcKeown and M. E. Curtis (Eds.). The nature of vocabulary acquisition. Hillsdale, NJ: Lawrence Erlbaum Associates.

[21] Oxford, R. L. \& Nyikos, M. (1989). Variables affecting choice of language learning strategies by university students. Modern Language Journal, 73 (3), 291-300.

[22] Oxford, R. L. \& Scarcella, R. C. (1994). Second language vocabulary learning among adults: State of the art in vocabulary instruction. System 22(2), 231-243.

[23] Salimi, M. R. (2000). Affective factors n learning English: A study of the filters. Unpublished Master's thesis. Shiraz University, Shiraz, Iran.

[24] Sanaoui, R. (1996). Processes of vocabulary instruction in 10 French as second language classrooms. The Canadian Journal Review 52(4), 529-548.

[25] Sedaghat, M. (2001). The effects of attitudes, motivation (instrumental and integrative), and Proficiency level on the use of listening comprehension strategies by Iranian female EFL Students. M.A thesis. Shiraz University.

[26] Swain, M. (1996). Integrating language and content in immersion classrooms: Research prospectives. The Canadian Modern Language Review, 52 (4), 529-548.

[27] Swanborn, M. S. L., \& de Glopper, K. (1999). Incidental word learning while reading: A meta analysis. Review of Educational Research, 69(3), 261-285.

[28] Tudor, I. \& Hafiz, F. (1989). 'Extensive reading as a means of input to L2 learning.' Journal of Research in Reading 12(2), 164-78.

[29] Wind, M. \& Davidson, M. (1969). 'Facilitation of paired-associate learning by language context.' Psychonomic Science 15, 4, 184-85.

[30] Wlodwoski, R. J. (1985). Enhancing adult motivation to learn. San Fransisco: Jossey bass.

Kamal Heidari Soureshjani holds M.A in TEFL from Shiraz University and is a Young Researchers Club Member. He taught English courses and IELTS at different institutes in Shiraz and is presently the academic member of Azad University, Shahrekord branch. He has also published papers in journals including IJLS.

Noushin Naseri holds M.A in TEFL from Shiraz University. She has taught different English language courses and also IELTS for several years. She also used to teach at Islamic Azad Universities in Kerman. 